ARTIGO

\title{
O TRABALHO DE PROJETO NA PRÁTICA DE ENSINO DE FUTUROS PROFESSORES DO ENSINO BÁSICO EM PORTUGAL
}

\author{
PROJECT-BASED LEARNING IN THE PRACTICUM OF FUTURE BASIC EDUCATION \\ TEACHERS IN PORTUGAL
}

\section{TRABAJO DE PROYECTO EN LA PRÁCTICA DOCENTE DE FUTUROS PROFESORES DE EDUCACIÓN BÁSICA EN PORTUGAL}

Tiago Bruno Correia Tempera ${ }^{1}$ 0000-0003-4250-5747

Luís Alexandre da Fonseca Tinoca² ${ }^{2} 0000-0001-6950-3245$

${ }^{1}$ Instituto de Educação da Universidade de Lisboa - Lisboa, Portugal; tiagot@eselx.ipl.pt

${ }^{2}$ Instituto de Educação da Universidade de Lisboa - Lisboa, Portugal; ltinoca@ie.ulisboa.pt

\begin{abstract}
RESUMO:
A prática de ensino supervisionada do futuro professor é um período determinante para o desenvolvimento das suas práticas educativas e competências profissionais. Apesar de valorizarem a sua natureza ativa e interdisciplinar, muitos professores têm demonstrado dificuldades em implementar o Trabalho de Projeto nas suas práticas. Este estudo visa conhecer a forma como os futuros professores do $1 .^{\circ}$ Ciclo do Ensino Básico, em Portugal, integram o Trabalho de Projeto nos seus estágios de prática pedagógica. Os dados foram recolhidos através de entrevistas em grupo focal a dois grupos de estudantes de instituições diferentes, mas com modelos de formação semelhantes. Os resultados demonstram que os futuros professores valorizam e procuram contemplar o Trabalho de Projeto nas suas práticas educativas, atravessando algumas dificuldades na implementação desta metodologia, que poderiam ser atenuadas através de uma maior concertação entre a instituição formadora e as escolas de estágio, de modo a minimizar o hiato existente entre os modelos pedagógicos abordados na formação e as realidades educativas encontradas.
\end{abstract}

Palavras-chave: formação inicial; método de projeto; prática de ensino.

\begin{abstract}
:
The supervised teaching practice of a future teacher is a determining period for the development of their educational practices and professional skills. Despite valuing its active and interdisciplinary nature, many teachers have shown difficulties in implementing the Projectbased Learning method in their practices. This study aims to understand how future teachers of the 1st Cycle of Basic Education, in Portugal, integrate Project-based Learning in their practicum. Data were collected through focus group interviews with two groups of students from different institutions, but with similar training models. The results demonstrate that future teachers value and seek to include Project-based Learning in their educational practices, going through some difficulties in the implementation of this method, which could be alleviated through greater consultation between training institutions and internship schools, in order to minimize the gap between the addressed pedagogical models and the educational realities found.
\end{abstract}

Keywords: initial teacher education; project-based learning; teaching practice.

\section{RESUMEN:}


prácticas educativas y competencias profesionales. A pesar de valorar su carácter activo e interdisciplinario, muchos profesores han mostrado dificultades para implementar Trabajo de Proyecto en sus prácticas. Este estudio tiene como objetivo comprender cómo los futuros docentes del 1er Ciclo de Educación Básica, en Portugal, integran el Trabajo de Proyecto en sus prácticas pedagógicas. Los datos fueron recolectados a través de entrevistas de grupos focales con dos grupos de estudiantes de diferentes instituciones, pero con modelos de formación similares. Los resultados demuestran que los futuros profesores valoran y buscan incluir el Trabajo de Proyectos en sus prácticas educativas, pasando por algunas dificultades en la implementación de esta metodología, las cuales podrían ser paliadas a través de una mayor consulta entre la institución formadora y las escuelas de práctica, con el fin de minimizar la brecha entre los modelos pedagógicos abordados en la formación y las realidades educativas encontradas.

Palabras clave: formación inicial de profesores; práctica pedagógica; trabajo de proyecto.

\section{Introdução}

Ao longo da vida, os professores enfrentam um processo contínuo de crescimento pessoal e profissional que não se restringe à aprendizagem de conhecimentos e competências. Em termos de investigação, Kostiainen et al. (2018) referem que não têm existido muitos estudos que se foquem nas novas abordagens educativas na formação de professores, nem como estas têm sido experienciadas pelos futuros professores.

Rangel e Gonçalves (2011) criticam as abordagens tradicionalistas do ensino centradas essencialmente no professor, defendendo metodologias ativas baseadas em princípios socioconstrutivistas e interdisciplinares, havendo uma preocupação em estabelecer relações entre o conhecimento teórico e a vida real.

A Metodologia de Trabalho de Projeto (MTP) é uma metodologia de ensino ativa que permite a interligação dos saberes e conteúdos de várias áreas curriculares. Vários professores têm recorrido ao uso desta metodologia nas suas práticas educativas para melhor preparar os alunos para se tornarem cidadãos ativos no século XXI (CONDLIFFE et al., 2017). Contudo, muitos professores ainda encontram dificuldades em implementar este tipo de metodologias com os seus alunos, apesar de valorizarem métodos de aprendizagem ativos e colaborativos (DIESEL; MATOS, 2019), havendo a necessidade de promover o desenvolvimento de competências de integração curricular na FI.

Galvão e Reis (2002) reforçam a importância da supervisão nos estágios de Prática de Ensino Supervisionada (PES), na medida em que possibilita que os futuros professores apliquem metodologias ativas abordadas durante a FI, ao invés de reproduzirem os modelos educativos que experienciaram no seu percurso escolar. Amorim e Fernandes (2018) reforçam 
Tiago Bruno Correia Tempera • Luís Alexandre da Fonseca Tinoca

esta ideia valorizando a dimensão prática da profissão que deveria ser complementar à dimensão teórica.

Em Portugal, a FI de professores do $1 .^{\circ}$ Ciclo do Ensino Básico $\left(1 .^{\circ} \mathrm{CEB}\right)$ tem duas componentes: uma licenciatura em Educação Básica com a duração de 3 anos, constituída como um tronco comum para profissionais que queiram trabalhar com crianças dos 0 aos 6 anos de idade, seguida de um mestrado profissionalizante em Ensino do $1 .^{\circ} \mathrm{CEB}$ (ou das suas variantes Pré-escolar e $1 .^{\circ} \mathrm{CEB}$; ou $1 .^{\circ}$ e $2 .^{\circ} \mathrm{CEB}$ ), com a duração de 2 anos e com uma forte incidência na componente didática e de PES. Esta formação segue o modelo preconizado pelo Decreto n. ${ }^{\circ}$ 43/2007, da responsabilidade conjunta do Ministério da Educação e do Ministério da Ciência, Tecnologia e Ensino Superior que contempla orientações primeiramente para a formação científica e posteriormente para a formação didática dos estudantes. Desde a implementação do processo de Bolonha em Portugal em 2007, que trouxe mudanças significativas na estrutura e conceptualização da FI de professores, observou-se uma mudança conceptual na forma de perspetivar o ensino e a aprendizagem, colocando o ensino tradicionalista ou transmissivo como métodos não preferenciais.

Previamente à presente investigação, foi realizado um estudo com as instituições de ensino superior nas quais os participantes realizaram a sua FI (TEMPERA; TINOCA, 2020). Tendo como objetivo conhecer a natureza da abordagem da MTP nos currículos de FI de instituições do ensino superior, os resultados demonstraram que as instituições procuram integrar a MTP no âmbito dos seus cursos em termos teóricos, didáticos ou experienciais como método de trabalho de Unidades Curriculares. Os resultados revelaram também que, apesar valorizarem a utilização desta metodologia nos estágios de PES, as instituições encontram alguma dificuldade em promover mais experiências significativas de trabalho de projeto durante os cursos, de modo a que os estudantes se sintam mais confiantes para o incorporar nas suas práticas.

Este estudo tem como objetivo principal conhecer a forma como os futuros professores do 1. CEB integram a MTP na sua PES, procurando responder a questões como: "Que importância os futuros professores conferem à MTP para a aprendizagem dos alunos?”; "De que modo utilizam a MTP na sua PES?”; “Qual a natureza das dificuldades na aplicação da MTP durante a PES?” e “Qual o nível de preparação sentido pelos estudantes para o desenvolvimento de projetos com os alunos?”. Não será nossa intenção comparar estudantes, nem instituições formadoras, mas perceber como diferentes modelos de estágio, de contexto e 
de supervisão, podem influenciar a utilização da MTP e de perspetivar a sua utilização no futuro.

\subsection{Metodologia de Trabalho de Projeto}

Sendo o trabalho de projeto uma metodologia de ensino ativa centrada no aluno, Vasconcelos (2011) considera que o trabalho de projeto contribui para atribuir significado às aprendizagens, ao envolver os participantes na resolução de problemas, tomada de decisões e na procura de respostas. Todo o processo percorrido permite o desenvolvimento de competências essenciais a uma sociedade, como a recolha e tratamento de dados, a aprendizagem social do trabalho em grupo, a tomada de decisões e o espírito de iniciativa e criatividade.

Neste sentido, Estrela (2001) defende a inclusão de práticas de trabalho de projeto na FI de professores. Colocar os estudantes da FI em contacto prático com esta metodologia, permitelhes tornarem-se responsáveis pelo seu próprio percurso educativo através de experiências e conhecimentos para além dos adquiridos academicamente, indo ao encontro de um maior isomorfismo entre formação e ensino.

Sendo o problema de partida decorrente da vida das crianças e das suas experiências, um trabalho desta natureza permite a contribuição e articulação de todas as áreas curriculares, que partem da temática central, para a resolução do problema. Para este fim, todo o processo desenvolvido na execução de um projeto torna-se relevante. Silva (2005) considera que todas as fases de um trabalho de projeto contribuem para uma construção progressiva do conhecimento, envolvendo a conceção, a tomada de decisões que parte da ideia inicial, o planeamento da ação, a ação propriamente dita e a avaliação do processo. Para além dos aspetos da integração curricular, característica própria dos trabalhos de projeto, nos quais o recurso a diferentes áreas curriculares permite a incorporação e a interligação de um elevado número de fontes, conceitos e percursos, Rangel e Gonçalves (2011) consideram que a aplicação desta metodologia em contextos educativos favorece uma educação motivada, participada, partilhada, cooperativa e integrada.

No seu estudo, Virtue e Hinnant-Crawford (2019) concluem que os alunos valorizam o trabalho desenvolvido quando trabalham em projetos, na medida em que conseguem articular os resultados do seu trabalho com a sua aplicabilidade no mundo real. Choi et al. (2019) referem que as a utilização da MTP poderá ser vantajosa também para os professores, dado que as 
experiências educacionais de qualidade que promovem com os alunos, conduzem a um aumento da sua autoeficácia enquanto professores.

Deste modo, MTP é considerado como uma pedagogia de fronteira (VASCONCELOS, 2011), um método de ensino eficaz, aumentando a qualidade das aprendizagens dos alunos comparativamente com os métodos transmissivos de ensino, possibilitando aos alunos adquirirem competências que lhes permite uma conexão com o mundo real e resolução de problemas de natureza diversa.

A MTP está também associada positivamente com o envolvimento dos alunos nas atividades desenvolvidas, valorizando as aprendizagens realizada ao longo de todo o percurso, permitindo que estes se impliquem na procura de soluções através das questões levantadas, debate de ideias, planeamento e comunicação com os outros (CHOI; LEE; KIM, 2019).

\subsection{Formação inicial de professores}

As condições favoráveis para desenvolver experiências significativas na formação de professores poderão ser criadas através de um curso que estruture processos sociais e que permita que os estudantes experienciem os temas abordados na prática e que desenvolvam as experiências à luz da teoria (KOSTIAINEN et al., 2018). Para estes autores, uma pedagogia da formação de professores que combine experiências práticas significativas e reflexão, é essencial para os futuros professores compreenderem a conexão entre a teoria e a prática. Neste sentido, Nicu (2015) reforça que há uma necessidade de desenvolver políticas educacionais fortes na FI de professores e uma necessidade de uma formação contínua para os professores do ensino superior, de modo a estarem a par de novos métodos de ensino e aprendizagem. Na perspetiva de Niemi (2002), se a FI não for capaz de promover suficientes experiências ativas de aprendizagem com qualidade aos estudantes, poderá conduzir ao abandono das metodologias de ensino ativas por parte dos futuros professores, já que estes não possuem um metaconhecimento sobre a aprendizagem e necessitam de oportunidades de prática destas metodologias durante o curso, para reconhecer a sua importância.

Lasauskiene e Rauduvaite (2015) recomendam que se introduzam soluções a nível institucional para desenvolver a implementação da MTP como uma estratégia de ensino de modo a melhorar as competências dos próprios professores do ensino superior ao nível da colaboração entre pares e mudança de atitude perante diferentes métodos de estudo. Bronkhorst et al. (2014) referem que as pedagogias inovadoras de formação de professores podem criar resistências por parte dos estudantes e dos próprios formadores. Sugerem, portanto, que não 
Tiago Bruno Correia Tempera • Luís Alexandre da Fonseca Tinoca

sejam apenas os estudantes a ultrapassar essas resistências, como também os formadores, esforçando-se para irem mais ao encontro das necessidades dos seus formandos.

Alguns estudos (LEE et al., 2014; NICU, 2015) relatam a experiência de incorporar a MTP em cursos de formação de professores, revelando-se eficaz no desenvolvimento do conhecimento interdisciplinar, na compreensão e aplicação de conceitos científicos, e na motivação e responsabilidade dos estudantes perante o seu próprio processo de aprendizagem. Contudo, Lee et al. (2014) consideram que a implementação da MTP no ensino superior não é um processo fácil, reconhecendo-lhe algumas dificuldades como alinhar os projetos com as necessidades e objetivos das diferentes disciplinas do curso, manter a calendarização semestral definida e assegurar o trabalho de grupo entre os professores da instituição, de modo a minimizar as resistências dos estudantes. Apesar dos desafios encontrados, os autores referem que os professores que participaram no seu estudo e se dispuseram a redefinir as suas práticas de ensino ao adotar a MTP como metodologia da sua disciplina, sentiram que os benefícios para a aprendizagem dos estudantes fizeram valer o tempo e o esforço despendidos.

Pode então considerar-se que o conhecimento dos conteúdos a ensinar não é suficiente para a atividade profissional de um professor, sendo necessário investir na abordagem de metodologias que procurem dotar os professores de competências críticas e reflexivas, apoiadas pelo conhecimento pedagógico dos conteúdos. Alicerçando-se na ideia de que a formação de professores conduz a uma aquisição de saberes, perícias e competências necessárias para um maior desenvolvimento profissional ao longo do tempo, Kwietniewski (2017) refere que o maior obstáculo à implementação da MTP são os próprios professores, na medida em que não se sentem devidamente preparados e que necessitam de mais formação nesse âmbito.

\subsection{Prática de Ensino Supervisionada}

Alicerçando-se na ideia de que os professores devem aprender com as suas práticas letivas, Darling-Hammond e Baratz-Snowden (2007) assumem que um currículo de formação de professores não se deve limitar à aquisição de saberes, mas também permitir que os estudantes procurem e apliquem novas estratégias em situações nas quais os modelos não são suficientes. Neste sentido, as práticas pedagógicas durante os estágios são de extrema importância, ao permitir aos estudantes confrontarem os modelos teóricos com situações concretas de aprendizagem.

Os estágios profissionalizantes da FI podem ser considerados como a oportunidade dos futuros professores para vivenciarem o trabalho pedagógico numa fase inicial de formação 
profissional (FERREIRA et al., 2020). Neste sentido, a PES pode ser definida como a aplicação em contextos específicos do conhecimento científico e pedagógico, abordado na FI e são estas práticas que estabelecem a base para o desenvolvimento profissional de um professor através do desenvolvimento de competências a partir da aplicação em contexto real dos conhecimentos adquiridos (ALARCÃO; TAVARES, 2018; GALVÃO; REIS, 2002).

Deste modo, os estágios de PES têm um papel fundamental na FI constituindo-se como o primeiro contacto com a profissão docente e desafiando as conceções iniciais do que é ser professor, adquiridas durante o seu próprio percurso escolar (GALVÃO; REIS, 2002). Os mesmos autores reforçam a importância da supervisão e reflexão sobre as práticas na construção da identidade docente, de modo a que os futuros professores apliquem as metodologias abordadas durante a FI, ao invés de reproduzirem os modelos que tiveram durante a sua escolaridade. Reconhecem também algumas dificuldades inerentes a um estágio de qualidade, na medida em que (i) as escolas e as instituições de ensino superior têm, frequentemente, visões distintas e difíceis de conciliar, (ii) o elevado número de estudantes a necessitar de uma escola para estagiar nem sempre permite a seleção de locais de estágio de qualidade, (iii) as práticas pedagógicas são, por vezes, pouco diversificadas e desligadas das componentes da FI, centrando-se na metodologia do professor titular da turma. Neste sentido, o papel do supervisor e das instituições formadoras é fundamental na tentativa de inserir os estudantes em contextos de qualidade, com práticas pedagógicas diversificadas, mantendo os estudantes motivados e estimulando o pensamento reflexivo para ultrapassar as dificuldades inerentes a um estágio de PES.

Na perspetiva dos estudantes, os estágios de PES compreendem a fase mais importante da sua formação para professores (NIEMI, 2002). Nesta fase da formação, Smith (2015) considera o papel do supervisor como fulcral, cabendo-lhe a responsabilidade de introduzir o campo de prática aos futuros profissionais. Para além do supervisor institucional, Garmston et al. (2002) consideram que o papel do professor cooperante, o profissional em cuja sala de aula o estudante realiza a sua PES, é igualmente relevante para a formação do futuro professor. Ambos devem estabelecer um plano coordenado e assumir-se como mediadores entre o estagiário e o ambiente formativo, no qual este constrói novos significados através da ação e da reflexão.

O pensamento reflexivo é entendido como um aspeto fundamental para a PES e na construção da identidade profissional de um professor, através de uma constante (re)avaliação das práticas educativas, de modo a melhorá-las (VUJIČIĆ; BONETA; IVKOVIĆ, 2015). 
Tiago Bruno Correia Tempera • Luís Alexandre da Fonseca Tinoca

Segundo Sutherland et al. (2010), é na fase de transição de estudante para professor, que os futuros professores criam a sua própria identidade profissional que se desenvolve através da interpretação e reinterpretação das suas experiências através da reflexão.

Em síntese, a PES visa o desenvolvimento, em contexto real, de competências de suporte ao desempenho profissional, bem como a resolução de problemas colocados pela prática docente no quotidiano das escolas. Supõe também a análise e reflexão da prática desenvolvida numa perspetiva de integração científico-pedagógica e teórico-prática. Neste sentido, constitui-se como um espaço de transferência para a ação profissional das aprendizagens realizadas nas outras componentes curriculares dos cursos de FI de professores, procurando integrar e transformar saberes disciplinares em saberes profissionais capazes de fundamentar e orientar a ação docente.

\section{Metodologia}

Este estudo está situado num paradigma fenomenológico-interpretativo (COHEN; MANION; MORRISON, 2018) procurando compreender o fenómeno investigado, interpretando-o sob o ponto de vista dos participantes e estabelecendo inferências através das situações particulares observadas. Existe, assim, a preocupação de compreender e interpretar as situações observadas tendo em conta as perspetivas dos seus intervenientes. Ao investigar as perspetivas dos futuros professores acerca dos processos e dinâmicas da PES pretende-se proporcionar uma melhor compreensão sobre as questões de investigação, levantando-se hipóteses de trabalho sobre as mesmas.

Os participantes deste estudo são dois grupos de futuros professores do $1 .^{\circ} \mathrm{CEB}$, finalistas dos cursos de mestrado profissionalizante de duas instituições do ensino superior com modelos de formação semelhantes, mas com diferentes currículos. Da instituição A (InstA) participaram oito estudantes e da instituição B (InstB) participaram cinco estudantes. A recolha de dados foi realizada após a conclusão do estágio profissionalizante, antes da entrega do relatório de PES, após o qual, os estudantes finalizam o curso e se tornam professores profissionalizados. Os estudantes foram selecionados através da indicação dos coordenadores dos cursos de mestrado e supervisores da PES, das duas instituições. Ambas as instituições contemplam o trabalho de projeto como metodologia inerente aos seus cursos. Os critérios de seleção dos professores tiveram em conta o conhecimento próprio dos coordenadores e supervisores, constituindo-se como dois grupos de estudantes que desenvolveram uma PES de qualidade e demonstraram capacidades críticas e reflexivas durantes os seus estágios. 
No seu percurso académico, os participantes de ambas as instituições tiveram contacto com a MTP durante a licenciatura através de algumas Unidades Curriculares que utilizavam esta metodologia como método de trabalho. Adicionalmente, os participantes da InstA frequentaram uma Unidade Curricular específica de Introdução à Prática Profissional, que lhes solicitava que aplicassem esta metodologia com alunos do $1 .^{\circ} \mathrm{CEB}$. No âmbito da PES dos mestrados não há qualquer solicitação metodológica específica para a implementação da MTP. Os estudantes foram colocados a pares em escolas do ensino público ou privado, em turmas de professores titulares (denominados professores cooperantes). Após tomarem conhecimento das características da turma e das metodologias adotadas, os estudantes procuraram seguir os princípios orientadores da instituição formadora, dos supervisores institucionais e dos professores cooperantes, procurando implementar metodologias ativas, sempre que possível. Os professores cooperantes dos estudantes da InstA seguiam princípios do Movimento da Escola Moderna, tendo por hábito desenvolver frequentemente trabalho de projeto com os alunos. Os professores cooperantes dos estudantes da InstB, adotavam metodologias diversificadas, desenvolvendo esporadicamente projetos com os seus alunos.

Para este estudo foram realizadas duas entrevistas semiestruturadas em grupo focal aos participantes de cada instituição do ensino superior, com o objetivo de conhecer as suas perspetivas acerca da utilização da MTP na PES e nas suas práticas futuras. As entrevistas foram baseadas num guião orientador previamente definido, e orientadas no sentido de conferir liberdade aos participantes para manifestar as suas opiniões. No início da entrevista foram dadas algumas indicações aos participantes no sentido de lhes dar a conhecer as características de uma entrevista desta natureza. Foi-lhes indicado que as questões seriam colocadas para todo o grupo e cada um responderia às que desejasse, completando ou refutando as opiniões manifestadas pelos demais participantes. As entrevistas em grupo focal permitem a recolha de dados através da interação de um grupo sobre um tópico apresentado pelo investigador, contribuindo para a compreensão desse tópico, na medida em que todos os participantes possuem características em comum, relevantes para a discussão (KRUEGER; CASEY, 2014). Permite, deste modo, compreender como este grupo de participantes pensa sobre os assuntos abordados, bem como retirar dados pertinentes acerca das suas práticas educativas, tendo em vista identificar aspetos que conduzam à sua melhoria. Devido à situação pandémica e de confinamento obrigatório em que o país se encontrava no decorrer do estudo, todas as entrevistas em grupo foram realizadas online, via plataformas de videoconferência. 
Posteriormente à recolha dos dados, estes foram sujeitos a uma análise de conteúdo (AMADO, 2017) e categorizados segundo aspetos comuns identificados, tendo em conta os objetivos do estudo. Os nomes dos futuros professores e das instituições são fictícios, mantendo o anonimato dos participantes e a confidencialidade dos dados.

\section{Discussão}

Através das entrevistas realizadas aos dois grupos de estudantes emergiram informações relevantes e implicações dos dados recolhidos, relacionando-se diretamente com as quatro questões de investigação, que serão o foco da apresentação e discussão dos resultados obtidos.

Questão de Investigação 1: Que importância os futuros professores conferem à MTP para a aprendizagem dos alunos?

Todos os futuros professores realçaram a importância e relevância da MTP na aprendizagem dos alunos, mesmo não sendo a única metodologia que utilizaram na sua PES.

Questionados acerca do que era, na sua opinião, aprender por projetos, a tendência geral dos grupos foi referir-se às suas vantagens e importância que lhe reconhecem.

O grupo da InstA afirma ser uma metodologia centrada nos alunos, potencializadora do desenvolvimento de "competências investigativas de organização da informação, análise dessa informação, e posterior comunicação do que foi recolhido ao longo do tempo" (Gonçalo, Entrevista). Célia acrescenta ainda o trabalho e o espírito de cooperação que se cria num trabalho desta natureza, bem como o envolvimento dos alunos no seu processo de formação.

Quanto ao grupo da InstB, as suas respostas focaram-se mais na preocupação do professor em transformar um tema num projeto, ao invés de o transmitir aos alunos. Na opinião de Carolina, para desenvolver um trabalho desta natureza tem de se ter em conta "o que o grupo pretende, os objetivos ou onde quero chegar com essas aprendizagens", aspeto reforçado por Neusa que afirma ser necessário atender "às necessidades daquela turma, do que (os alunos) necessitam". Os interesses e os gostos dos alunos como fator intrínseco ao trabalho de projeto também foi referido por Maria, havendo a necessidade se dar atenção "ao meio envolvente, à comunidade, escola e família das crianças para conseguirmos realizar um projeto consistente”. Concordando com o que foi mencionado, Joana considera necessário "partirmos do que eles querem trabalhar, dos seus interesses, dos gostos, para que eles estejam interessados e empenhados durante o projeto, para conseguirmos atingir os objetivos a que nos propusemos."

A importância que os futuros professores conferem à MTP na aprendizagem dos alunos, prende-se com as vantagens que lhe reconhecem, nomeadamente a motivação para aprender e 
Tiago Bruno Correia Tempera • Luís Alexandre da Fonseca Tinoca

o empenho, devido ao foco em temas ou problemas do seu interesse (CHOI; LEE; KIM, 2019) e ao desenvolvimento de competências sociais transversais ao currículo, como a cooperação e a comunicação (RANGEL; GONÇALVES, 2011). Apesar de terem experiências diferentes, os participantes revelam conceções similares acerca da MTP, em termos da natureza ativa desta metodologia.

Questionados especificamente acerca das vantagens que a MTP traz para a aprendizagem dos alunos, o grupo da InstA concorda com Daniela quando afirma que a MTP ajuda os alunos a desenvolver a sua autonomia ao serem eles próprios a construir o caminho até ao conhecimento, fazendo com que "essa construção do conhecimento a partir de dentro - não é alguém que lhes passa o conhecimento - faz com que, para além de adquirirem esses conhecimentos, adquiram competências para os desenvolver posteriormente quando saírem da escola”. Reiterando o que foi dito, Helena mostra alguma preocupação na questão da construção do conhecimento coletivo, no sentido em que sente que os alunos se dedicam bastante e dominam o tema que estão a trabalhar, mas há um desequilíbrio em relação aos temas dos outros grupos, aos quais só têm acesso na fase de comunicação:

É fácil eles compreenderem e adquirirem conhecimento em relação ao que estão a fazer, ao conteúdo que estão a trabalhar, mas em relação aos conteúdos que outros grupos estão a trabalhar e que eles não pesquisam, parece-me difícil eles conseguirem adquirir da mesma forma, porque não fizeram a investigação, só têm acesso à apresentação. Parece-me que há um desequilíbrio em relação aos conteúdos porque ficam a perceber muito bem aquilo que trabalharam, mas não em relação aos outros.

Elsa apressa-se a encontrar uma solução. Apesar de concordar que, com as comunicações, os conteúdos não são passados tão aprofundadamente como se os investigassem, esse facto poderia ser colmatado se criassem materiais de trabalho para os alunos, como "ficheiros para os colegas estudarem, ou fichas para o livro de estudo, ou um registo escrito para os colegas consultarem".

Através destas intervenções, é possível verificar-se a consciencialização para os desenvolvimento de competências transversais (VASCONCELOS, 2011), bem como uma preocupação e uma procura de soluções para desvantagens válidas apontadas à metodologia, demonstrando serem críticos e reflexivos quanto à aplicabilidade desta metodologia em contextos educativos (VIRTUE; HINNANT-CRAWFORD, 2019).

Face ao mesmo questionamento acerca das vantagens que reconhecem à MTP para a aprendizagem dos alunos, o grupo da InstB demonstrou mais dificuldade em pronunciar-se. Lara reconhece que é um desenvolvimento e uma aprendizagem graduais, mas não desenvolve a ideia. Face ao silêncio prolongado, foi-lhes questionado se um projeto que fosse capaz de interligar conhecimentos de várias áreas, seria uma mais-valia para os alunos. Agarrando nesse 
Tiago Bruno Correia Tempera • Luís Alexandre da Fonseca Tinoca

tópico Maria afirma considerar a interdisciplinaridade muito importante ao invés de estar a abordar uma área curricular isoladamente dado que "uma atividade pode ser muito rica em várias áreas de conteúdo e ser muito benéfica para o desenvolvimento crítico da criança". Concordando com a colega, Neusa afirma que, através de atividades interdisciplinares, se pode cativar os alunos para outras áreas em que não demonstram muito interesse. Estabelecendo-se novo momento de silêncio, foi-lhes lançado o tópico da importância das relações e competências sociais que se podem desenvolver durante um trabalho de projeto. Os acenos de cabeça revelaram que reconhecem a existência desse aspeto, mas o tópico não foi desenvolvido ou aprofundado pelos participantes.

A reduzida participação nesta questão e a linguagem corporal manifestada, faz-nos aperceber de que os participantes poderão reconhecer a importância da MTP, mas parecem não conhecer esta metodologia a fundo ou ter experienciado a sua aplicação de forma significativa, para se sentirem confortáveis a emitir opiniões sobre a mesma, reforçando a ideia da importância de experiências desta natureza na FI (KOSTIAINEN et al., 2018).

Questão de Investigação 2: De que modo os futuros professores utilizam a MTP na sua PES?

Os motivos porque os futuros professores decidem utilizar esta metodologia na PES prendem-se essencialmente com as metodologias previamente adotadas pelo professor cooperante.

No grupo da InstA, os professores cooperantes já utilizavam esta metodologia com os alunos, tendo os estudantes dado continuidade a um método de trabalho já existente. Inclusivamente, Daniela refere que esta metodologia “já estava a ser implementada desde o 1. ano. (Os alunos) eram do $4 .^{\circ}$ ano e já estavam muito habituados, faziam-no já de forma muito autónoma". Nesse sentido, todo o grupo teve oportunidade de realizar trabalhos de projeto de forma consistente, com horário semanal definido para o efeito. Contudo, a metodologia não era desenvolvida da mesma forma em todas as turmas. Em jeito de crítica, Francisca afirma que o trabalho que estava a ser desenvolvido na sua sala, não seguia linearmente os princípios da MTP:

Os trabalhos estavam a ser realizados individualmente. Quando chegámos à sala, cada menino já tinha escolhido o seu tema. E também foi saltada uma etapa. Toda a pesquisa foi realizada pela professora, que entregou aos alunos. Eles apenas resumiam a informação que lhes tinha sido dada.

Ana revê-se na mesma situação, revelando que, por estagiar num $1 .^{\circ}$ ano e os alunos ainda não possuírem muita autonomia, "nós procurámos a informação, tentámos com que a 
Tiago Bruno Correia Tempera • Luís Alexandre da Fonseca Tinoca

informação fosse direcionada às questões que tínhamos preparado com eles. Isso fez, na minha visão, perder a descoberta das crianças de procurarem respostas às suas perguntas".

Através deste segmento, denota-se uma valorização do processo de aprendizagem e a compreensão das fases da MTP (SILVA, 2005; VASCONCELOS, 2011), bem como um olhar crítico e reflexivo (VUJIČIĆ; BONETA; IVKOVIĆ, 2015) e um desejo de imprimir mudanças a contextos educativos ou a práticas já existentes, no sentido de melhorar a qualidade das aprendizagens dos alunos.

Quanto aos participantes da InstB tiveram mais dificuldade em implementar esta metodologia, dada a pouca abertura dos professores cooperantes para o fazer. Neusa considera que:

Foi muito difícil. Pelo menos no meu caso, havia entraves em tudo. Não foi assim tão fácil chegar com coisas novas, primeiro porque é pouco tempo para o que temos de fazer, e depois há toda uma envolvência. A escola, o agrupamento, entraves da pandemia, do próprio contexto, vícios dos próprios professores que são mais velhos e, se calhar, não aceitam tanto as coisas como outros... Há um grande choque de mentalidades, de comportamentos...

Joana confirma ter sentido algo semelhante, comparando dois professores cooperantes em dois estágios distintos:

Tendo em conta que tivemos dois estágios no $1 .^{\circ}$ ciclo, tive uma professora muito aberta, muito disposta a receber informações a tudo o que trouxéssemos de novo, e outro mais reticente, mais pé-atrás, "vamos mantendo o que está no manual, estou a dar isto no manual"... Foi mais difícil levar as crianças a trabalhar noutros moldes que não o livro e foi mais complicado nessa turma em concreto trabalhar por projetos.

Isabel também considera ter sido um trabalho difícil de desenvolver pois "os alunos não estavam habituados a projetos e era muito difícil para eles estarem em grupos, dispersavam imenso. Não conseguiam ser autónomos porque estavam habituados a ser orientados, a fazer a atividade do livro e não fazerem nada sozinhos".

A necessidade de se promover contextos de estágio de qualidade, bem como de uma estratégia consertada entre supervisor institucional e professor cooperante (GALVÃO; REIS, 2002; GARMSTON; LIPTON; KAISER, 2002), é notória nos testemunhos dos participantes, na medida em que reconhecem limitações nos seus modelos de estágio, sentindo que as suas próprias intencionalidades educativas e intervenções ficaram comprometidas.

Questionados acerca do modo como preparavam as intervenções de momentos de trabalho de projeto, o grupo da InstA focou-se essencialmente na questão da pesquisa individual sobre os temas, para que melhor pudessem apoiar os alunos no desenvolvimento dos trabalhos, e no auxílio à formulação de questões. Daniela afirma que realizou pesquisas em relação aos temas em que não se sentia muito à vontade e que "o apoio que dava não era em relação ao 
conteúdo, mas ajudá-los a formular as questões... O objetivo não era dar respostas às perguntas, mas ajudá-los a chegar lá. E nós também aprendíamos ao mesmo tempo”.

Não tendo havido muita experiência de trabalho de projeto nos estágios do grupo da InstB, foi-lhes questionado como se preparariam para um momento de trabalho de projeto com os alunos, quando fossem professores titulares de uma turma. Através de bastantes momentos de silêncio, os participantes referiram a necessidade de conhecer as características da turma, do projeto educativo da escola e da turma, mas não especificaram como desenvolveriam esta metodologia com os alunos. Apenas Isabel assume que se prepararia no sentido de tentar relacionar os projetos com os conteúdos que estivesse a abordar no momento.

A prontidão na participação de um grupo face ao outro nesta questão, leva-nos a valorizar as experiências significativas de intervenção na PES, sendo que a falta das mesmas pode levar a que os futuros professores tenham dificuldade em começar a desenvolver uma identidade profissional (GALVÃO; REIS, 2002; SUTHERLAND; HOWARD; MARKAUSKAITE, 2010; VUJIČIĆ; BONETA; IVKOVIĆ, 2015) e possam vir a abandonar metodologias em que se sentem pouco à-vontade, por não se sentirem convenientemente preparados (KWIETNIEWSKI, 2017; NIEMI, 2002), mesmo que as valorizem ou reconheçam as suas vantagens.

Questão de Investigação 3: Qual a natureza das dificuldades na aplicação da MTP durante a PES?

Os aspetos mencionados pelos futuros professores como limitadores ou que dificultam a MTP, prendem-se com a sua falta de experiência para conduzir momentos desta natureza, mas também, no caso dos participantes da InstB, com a falta de familiaridade dos alunos com este tipo de trabalho.

O grupo da InstA mostrou maior preocupação em refrear as suas intervenções, não dando respostas diretas às questões dos alunos, mas deixando-os descobrir por eles próprios. Beatriz reconhece que tinha dificuldade em distinguir "qual o momento em que tinha de intervir ou se devia deixá-los chegar lá, mesmo estando um bocadinho errado. Deveria dizer que não estava bem ou deixá-los descobrir? A minha dificuldade é essa, não intervir tanto, deixá-los descobrir sozinhos". Para Gonçalo, a maior dificuldade residiu na organização e seleção da informação pertinente para dar resposta às questões iniciais, referindo que:

\footnotetext{
Por vezes havia uma quantidade enorme de informação que não era relevante, mas por ser curiosa ou invulgar, eles queriam apresentar. Era a dualidade em conjugar o que era realmente importante e curiosidades que despertam a atenção do resto do grupo. De certa forma, a minha dificuldade foi passar esta ideia de que há informação relevante e outra que não é tão relevante e de que forma a podemos organizar.
} 
Tiago Bruno Correia Tempera • Luís Alexandre da Fonseca Tinoca

Elsa revelou que sentiu a mesma dificuldade, mas que a colmatou utilizando estratégias de questionamento, pois, segundo a própria, "eu não me sentia tão à vontade de lhes dizer (que não era importante) porque foram eles que recolheram. Ao fazer-lhes algumas perguntas eles percebiam um bocadinho que certa informação era acessória, mas não era sempre fácil aceitálo”. A preocupação demonstrada por Beatriz foi no sentido de conciliar os conteúdos do currículo com os temas dos projetos. Para a estudante, "às vezes, para seguir as motivações das crianças, muitas vezes fugimos dos conteúdos que temos programados. Pode tornar-se uma desvantagem se não conseguirmos conciliar", sendo necessário "ir ao encontro da vontade dos alunos, de quererem saber mais sobre um tema, mas manter a responsabilidade de ter um currículo que temos de abordar".

As dificuldades mencionadas por este grupo de estudantes relacionam-se com as próprias características ativas da metodologia, na qual se pretende que os alunos descubram as respostas para as suas questões numa perspetiva socioconstrutivista (CHOI; LEE; KIM, 2019; VIRTUE; HINNANT-CRAWFORD, 2019). No seguimento do que Vasconcelos (2011) defende, a integração curricular também é uma preocupação dos participantes, no sentido em que valorizam a interligação entre as várias áreas curriculares que compõem o currículo e se preocupam com a abordagem dos conteúdos programáticos de forma integrada.

No grupo da InstB, apenas Joana participou nesta questão referindo que a maior dificuldade seria estudar um tema em que não se sentisse à vontade e fazer a ligação com o currículo, referindo que "para transmitir as informações, tenho eu própria de estudá-las e estar atenta aos termos e a tudo o que envolve aquela matéria em si. Teria de aprofundar o tema". No seu discurso denota-se uma resistência em libertar-se de um método de ensino centrado no professor para um mais ativo, tal como sugerem Bronkhorst et al. (2014) havendo uma tendência para a transmissão de conhecimentos, o que contraria os princípios da MTP, pelo que nos podemos questionar como conciliaria a aprendizagem centrada no aluno, característica desta metodologia, com a necessidade de transmitir informação correta que a própria pesquisou.

Questão de Investigação 4: Qual o nível de preparação sentido pelos estudantes para o desenvolvimento de projetos com os alunos?

Todos os participantes deste estudo tiveram contacto com a MTP durante a sua FI, quer em termos experienciais, como metodologia adotada por algumas Unidades Curriculares do curso, quer em termos teóricos e didáticos. No entanto, enquanto que os participantes da InstA sentem que a possibilidade de aplicação da MTP nos estágios de PES foi determinante para a 
Tiago Bruno Correia Tempera • Luís Alexandre da Fonseca Tinoca

sua preparação, os participantes da InstB reconhecem que a preparação para este tipo de metodologia foi insuficiente, por não terem tipo oportunidade de a aplicar de forma consistente.

Durante a entrevista ao grupo da InstA, vários testemunhos reforçaram a ideia de que a FI teve um papel essencial na sua preparação. Beatriz valoriza a abordagem teórica acerca da metodologia, mas confessa que foi com a prática que realmente compreendeu "como funciona na realidade". Daniela compara dois estágios, em que um seguia predominantemente o método transmissivo, no qual foi ela a implementar a MTP, e o mais recente, no qual os alunos já estavam habituados a este tipo de trabalho. A estudante valoriza o facto de ter estagiado num contexto de qualidade, sentindo que "quem fica nesses contextos (mais tradicionalistas) acaba por ficar em desvantagem em relação aos restantes (colegas)". E Gonçalo reflete acerca de toda a sua FI, já que fez a licenciatura numa outra instituição e o mestrado na InstA:

Fiquei um pouco perdido quando começaram a falar nestes assuntos. Foram
proporcionadas as condições e oportunidades para que nós pudéssemos desenvolver
essas capacidades. Não trazendo bases da licenciatura, ou quase nenhumas, sobre
estes aspetos, chegado ao mestrado, houve essa preparação. De qualquer forma, só
senti que estava realmente preparado para trabalhar nesses moldes quando fui para a
prática.

Os participantes da InstB revelaram um discurso diferente. Quando questionados acerca da preparação conferida pela FI para trabalho por projetos, nenhum participante demonstrou vontade em falar, tendo a maioria encolhido os ombros. Com alguma resistência, foram demonstrando a razão do seu desconforto. Maria confessou que os formadores e supervisores incentivam à utilização de metodologias ativas, mas sente que "faltam as bases. Ficava tudo no ar, muito aquém. Então na licenciatura nem se fala (da metodologia)". Lara sente que a MTP foi apenas abordada no âmbito dos estágios tecendo algumas críticas à FI: "O trabalho de projeto foi mais trabalhado na altura das planificações e dos próprios estágios, do que nas aulas. Só quando chegamos aos estágios é que os professores se lembram de tínhamos de falar disso". Apenas Isabel e Joana confessaram sentir-se preparadas para desenvolver a MTP com os alunos, devido à experiência que tiveram na licenciatura que frequentaram, curiosamente, na InstA, afirmando que "já na licenciatura senti muita preparação para trabalhar em projetos" (Isabel, Entrevista) e "senti-me à vontade para aplicar nos estágios, porque já vinha preparada. Por isso no mestrado fiz sempre trabalho de projeto nos estágios todos” (Joana, Entrevista).

No discurso dos participantes é clara a importância que conferem à PES no decorrer da FI, dando-lhes a oportunidade de estabelecer relações entre os modelos teóricos com situações concretas de aprendizagem (DARLING-HAMMOND; BARATZ-SNOWDEN, 2007). Verifica-se também uma escassez ou dificuldade em reconhecer experiências de trabalho de 
Tiago Bruno Correia Tempera • Luís Alexandre da Fonseca Tinoca

projeto durante a sua FI que, apesar contempladas nos cursos, parecem não ter sido suficientemente significativas, ao contrário do que sugerem Kostiainen et al. (2018).

Considerando importante refletir acerca do que poderia ser complementado da FI, foilhes solicitado que identificassem os aspetos que considerassem mais pertinentes. Em ambas as instituições, todos os estudantes referiram o tempo reduzido de PES, afirmando que necessitavam de mais tempo de prática durante a FI, para se sentirem mais preparados. O grupo da InstA ainda acrescenta aspetos como a abordagem a metodologias diversificadas, para ficarem preparados para outros tipos de contextos de ensino (Ana, Entrevista), e mais vivências e experiências de MTP durante toda a FI, na medida em que "era uma mais valia para quando fossemos aplicar no mestrado. Num sentido pedagógico, seria muito mais fácil entender essa prática, porque experimentámos enquanto alunos" (Beatriz, Entrevista).

Para além da necessidade de mais tempo de contacto com realidades educativas, os futuros professores sentem a necessidade de realizar os seus estágios em contextos ricos de aprendizagem, com professores cooperantes que utilizam práticas pedagógicas diversificadas, tal como sugerem Galvão e Reis (2002). Na perspetiva dos estudantes, a compreensão do alcance das metodologias ativas só será possível com o enriquecimento de referenciais práticos (CRUZ, 2017) que a formação não foi capaz de oferecer na totalidade.

Independentemente do seu percurso formativo, todos os participantes entendem que a MTP é significativa, não só na aprendizagem dos alunos, como também na sua própria formação enquanto professores. Questionados acerca do papel da metodologia na sua formação e desenvolvimento profissional, Elsa da InstA refere que "foi importante ver que é possível centrar as aprendizagens nos alunos. E o trabalho de projeto é uma das melhores metodologias para centrarmos o ensino neles. Permitiu-nos perceber o que podemos vir a fazer enquanto professores". E Daniela da mesma instituição reforça esta ideia referindo que:

Este tipo de trabalho é importante, não só para os alunos como também para nós, até
para nos ajudar a definir o nosso papel em sala de aula. Em contextos com estas
práticas, faz-nos refletir sobre o nosso papel. Para mim o trabalho de projeto deixou-
me isso muito claro, eu não precisava de ir lá ensinar, eles eram capazes de aprender
por eles. A capacidade que eles têm de trabalhar autonomamente, também me faz
refletir nas competências que eu tenho de desenvolver. Faz-me pensar o que eu
poderia ter desenvolvido se tivesse feito este tipo de trabalho na minha escolaridade.

$\mathrm{Na}$ InstB, apenas Joana se pronunciou, referindo que "é uma metodologia muito próxima dos alunos, não tanto do professor. Isso leva-nos a um melhor método de ensino, não tão focados em nós e no programa, mas nos alunos e nos seus interesses".

Já tendo verificado a importância que os estudantes conferem à MTP para a aprendizagem dos alunos, verifica-se no seu discurso a valorização que lhe conferem também 
para os próprios. É-lhe reconhecida a relevância por considerarem que constituem experiências educativas de qualidade que aumentam a sua própria competência enquanto professores, tal como afirmam Choi et al. (2019).

O seguinte quadro (Quadro 1) procura sistematizar a informação obtida durante as entrevistas, segundo as características mais relevantes encontradas.

Quadro 1: Síntese das perspetivas de futuros professores acerca da MTP na PES

\begin{tabular}{|c|c|c|}
\hline MTP & InstA & InstB \\
\hline $\begin{array}{l}\text { Importância } \\
\text { para a } \\
\text { aprendizagem } \\
\text { dos alunos }\end{array}$ & $\begin{array}{l}\text { - Metodologia centrada no } \\
\text { aluno. } \\
\text { - Competências de } \\
\text { investigação. } \\
\text { - Sentido de cooperação. } \\
\text { - Construção do conhecimento. } \\
\text { - Desenvolvimento da } \\
\text { autonomia. }\end{array}$ & $\begin{array}{l}\text { - Centrado nos interesses dos } \\
\text { alunos. } \\
\text { - Interdisciplinaridade. }\end{array}$ \\
\hline $\begin{array}{l}\text { Implementação } \\
\text { na PES }\end{array}$ & $\begin{array}{l}\text { - Continuidade do trabalho do } \\
\text { professor cooperante. } \\
\text { - Preocupação em seguir as } \\
\text { fases da MTP. } \\
\text { - Orientação na formulação de } \\
\text { questões. } \\
\end{array}$ & $\begin{array}{l}\text { - Complemento ao trabalho do } \\
\text { professor cooperante. } \\
\text { - Preocupação em relacionar o } \\
\text { tema com o currículo. }\end{array}$ \\
\hline $\begin{array}{l}\text { Dificuldades na } \\
\text { implementação }\end{array}$ & $\begin{array}{l}\text { - Refrear a própria intervenção. } \\
\text { - Organização e seleção da } \\
\text { informação. } \\
\text { - Relacionar os temas ao } \\
\text { currículo. }\end{array}$ & $\begin{array}{l}\text { - Falta de hábitos de trabalho } \\
\text { de grupo por parte dos alunos. } \\
\text { - Falta de autonomia dos } \\
\text { alunos. } \\
\text { - Libertação de métodos } \\
\text { transmissivos. }\end{array}$ \\
\hline $\begin{array}{l}\text { Preparação } \\
\text { científica- } \\
\text { pedagógica }\end{array}$ & $\begin{array}{l}\text { - Boa preparação na FI. } \\
\text { - Tempo de PES determinante, } \\
\text { mas reduzido. } \\
\text { - Reconhecimento do papel do } \\
\text { professor. } \\
\text { - Necessidade de conhecerem } \\
\text { outras metodologias ativas na } \\
\text { FI. }\end{array}$ & $\begin{array}{l}\text { - Fraca preparação na FI. } \\
\text { - Tempo de PES determinante, } \\
\text { mas reduzido. } \\
\text { - Necessidade de estágios de } \\
\text { qualidade. }\end{array}$ \\
\hline
\end{tabular}

Fonte: Elaboração dos autores.

Os aspetos mencionados pelos participantes são complementares, no sentido em que ambos os grupos tiveram modelos semelhantes de FI, mas com currículos e realidades distintas, nomeadamente no que diz respeito à PES. São reconhecidas vantagens da implementação da MTP para a aprendizagem dos alunos e uma vontade de dar continuidade a esta metodologia quando forem professores titulares de uma turma. As realidades encontradas nos contextos de estágio, leva a que o grupo da InstA tenha tido mais experiências significativas de 
implementação da MTP, estando mais despertos para o papel do professor e para as dificuldades que possam surgir no decorrer do processo. $\mathrm{O}$ grupo da InstB revelou mais dificuldades em trabalhar segundo esta metodologia, por não se encontrar já implementada nas turmas onde estagiaram e, por conseguinte, os alunos terem dificuldade em desenvolver um tipo de trabalho que não estão habituados. Ambos os grupos referem a necessidade de obterem experiências de PES significativas através de contextos de estágio de qualidade, visando a redução das suas lacunas pedagógicas.

\section{Resultados}

Através dos testemunhos recolhidos é possível verificar-se que todos os participantes deste estudo valorizam a MTP na aprendizagem dos alunos, manifestando a intenção de continuar a utilizá-la nas suas práticas educativas futuras. Não sendo a única metodologia adotada na sua PES, é encarada como uma das mais relevantes para o desenvolvimento de competências e construção do conhecimento. Nesse sentido, é de realçar o papel da FI que, independentemente do tipo e grau de abordagem, foi capaz de incutir e destacar a importância de metodologias ativas, centradas no aluno, socioconstrutivistas e interdisciplinares, essenciais para a educação e preparação de um cidadão do séc. XXI (CONDLIFFE et al., 2017; RANGEL; GONÇALVES, 2011).

Verificamos também que o papel da PES na preparação dos futuros professores é determinante (GALVÃO; REIS, 2002), sendo essencial proporcionar aos estudantes contextos educativos propícios para observarem modelos pedagógicos de qualidade, ao mesmo tempo que lhes permite experimentarem diversas metodologias abordadas na sua formação. Os motivos porque os participantes deste estudo decidiram utilizar a MTP nas suas intervenções educativas prendem-se mais com a continuidade do trabalho do professor cooperante, do que com a intencionalidade pedagógica dos próprios. Fará todo o sentido desenvolver um trabalho mais estreito entre a instituição formadora e as escolas, de modo a minimizar o hiato existente entre os modelos pedagógicos abordados na formação e as realidades educativas encontradas nos estágios. Ao haver a necessidade de uma maior articulação entre teoria e prática (GATTI; NUNES, 2009; KOSTIAINEN et al., 2018), um trabalho concertado entre o supervisor institucional e o professor cooperante será fundamental (GARMSTON; LIPTON; KAISER, 2002), podendo inclusivamente ser criadas comunidades de prática, seminários ou formações para estes intervenientes, tendo em vista uma melhor preparação dos futuros professores para o ensino da atualidade. 
Tiago Bruno Correia Tempera • Luís Alexandre da Fonseca Tinoca

As dificuldades mencionadas pelos futuros professores na implementação da MTP, prendem-se essencialmente com a falta de experiências significativas durante a FI. Apesar de, nos cursos de FI, existirem algumas Unidades Curriculares que utilizam esta metodologia como método de trabalho, parecem não ser suficientes para os alunos reconhecerem modelos pedagógicos que, mais tarde, poderiam replicar com os seus alunos. Esta dificuldade no isomorfismo entre formação e ensino (ESTRELA, 2001) pode dever-se ao facto de não ser explícito e claro para os estudantes, havendo a necessidade de os formadores de reforçarem o tipo de trabalho que estão a desenvolver com os mesmos, demonstrando-lhes as potencialidades e a aplicabilidade da metodologia em contextos educativos. Será essencial criar um espírito colaborativo no próprio corpo docente das instituições formadoras, tendo em vista a concertação de estratégias educativas que promovam metodologias ativas explícitas e adequadas, reduzindo a resistência dos estudantes à sua implementação (LEE et al., 2014).

Apesar de valorizarem a sua FI, os estudantes revelam sentir que o tempo de PES é bastante reduzido, comparativamente às suas necessidades. Com a uniformização da estrutura e conceptualização da FI de professores em Portugal, através da implementação do processo de Bolonha, foi estabelecido um número fixo de ECTS (European Credit Transfer System) para cada componente de formação, incluindo a Iniciação à Prática Pedagógica. Neste sentido, todas as instituições possuem o mesmo número de ECTS que disponibilizam aos alunos, fazendo apenas a gestão da sua distribuição ao longo dos cursos. Deste modo, a sugestão e solicitação dos estudantes em aumentar o número de horas de PES será, no panorama atual, impossível de concretizar, dado que as instituições se regem obrigatoriamente pelo Decreto n. ${ }^{\circ}$ 43/2007, que define as condições necessárias à obtenção de habilitação profissional para a docência. Poderão, no nosso entender, oferecer oportunidades de contacto dos futuros professores com realidades educativas diversificadas, através de ofertas internas de formação ou de Unidades Curriculares opcionais, de modo a colmatar as necessidades dos estudantes. Parece-nos uma alternativa viável, exequível e relevante, tendo em conta os testemunhos generalizados dos futuros professores em FI.

Existem algumas limitações a este estudo derivadas, sobretudo, à natureza subjetiva das opiniões e interpretação dos participantes acerca do que experienciaram durante a sua FI. O estudo é baseado nas perspetivas de um número reduzido de futuro professores que aceitaram realizar a entrevista, não sendo representativo das opiniões de todos os estudantes dos cursos. Contudo, constitui-se como uma amostra, cujos pontos de vista manifestados refletem outras opiniões recolhidas através de questionários de avaliação dos cursos e de conversas informais 
entre colegas e entre estudantes e formadores. Um estudo longitudinal ao longo da formação de um grupo de estudantes poderia ser significativo, de modo a identificar-se os momentos específicos e as necessidades complementares de formação dos futuros professores.

As realidades distintas com que nos deparámos através das entrevistas realizadas aos estudantes de duas instituições do ensino superior permitiu-nos aperceber como princípios de formação semelhantes, mas com diferentes modelos de estágio, de contextos e de supervisão podem influenciar a utilização da MTP como estratégia de ensino e de perspetivar a sua implementação no futuro. Verificamos que os estudantes que tiveram oportunidade de observar e implementar a MTP na sua PES, aproveitaram convenientemente este benefício, tendo ficado rendidos às potencialidades educativas desta metodologia. Consideramos, deste modo, que as experiências que os futuros professores adquirem na FI são essenciais para a construção de uma identidade profissional que se inicia na própria formação, havendo a responsabilidade por parte das instituições formadoras de proporcionar ambientes educativos de qualidade, seja no âmbito das Unidades Curriculares dos cursos, ou nos estágios profissionalizantes.

\section{Referências}

ALARCÃO, Isabel; TAVARES, José. Supervisão da Prática Pedagógica - Uma

Perspectiva de Desenvolvimento e Aprendizagem. 2nd ed. Coimbra: Almedina, 2018. AMADO, João. Manual de investigação qualitativa em educação. $3^{\mathrm{a}}$ ed. Coimbra: Coimbra: Imprensa da Universidade de Coimbra, 2017. https://doi.org/10.14195/978-989-260879-2.

AMORIM, Aline; FERNANDES, Maria José. A Formação Inicial, a Prática Pedagógica e o Processo de se Tornar Professor. Práxis Educacional, vol. 14, no. 30, p. 85-110, 2018. https://doi.org/https://doi.org/10.22481/praxis.v14i30.4362.

BRONKHORST, Larike H.; KOSTER, Bob; MEIJER, Paulien C.; WOLDMAN, Nienke; VERMUNT, Jan D. Exploring student teachers' resistance to teacher education pedagogies. Teaching and Teacher Education, vol. 40, p. 73-82, 2014. DOI 10.1016/j.tate.2014.02.001. Available at: http://dx.doi.org/10.1016/j.tate.2014.02.001.

CHOI, Junghee; LEE, Ju Ho; KIM, Booyuel. How does learner-centered education affect teacher self-efficacy? The case of project-based learning in Korea. Teaching and Teacher Education, vol. 85, p. 45-57, 2019. DOI 10.1016/j.tate.2019.05.005. Available at: https://doi.org/10.1016/j.tate.2019.05.005. COHEN, Louis; MANION, Lawrence; MORRISON, Keith. Research methods in education. 8th ed. [S. l.]: Routledge Falmer, 2018.

CONDLIFFE, Barbara; QUINT, Janet; VISHER, Mary G; BANGSER, Michael R; DROHOJOWSKA, Sonia; SACO, Larissa; NELSON, Elizabeth. Project-Based Learning: A Literature Review. [S. l.: s. n.], 2017. Available at: https://s3-us-west1.amazonaws.com/ler/MDRC+PBL+Literature+Review.pdf. CRUZ, Giseli Barreto da. Ensino de didática e aprendizagem da docência na formação inicial de professores. Cadernos de Pesquisa, vol. 47, no. 166, p. 1166-1195, 2017. https://doi.org/10.1590/198053144323. DARLING-HAMMOND, Linda; BARATZ-SNOWDEN, Joan. A good teacher in every classroom: Preparing the highly qualified teachers our children deserve. Educational 
Horizons, vol. 85, no. 2, p. 111-132, 2007. .

DIESEL, Daniela; MATOS, João Filipe. Espaços educativos inovadores e o olhar dos professores para a ação docente. Educação e Cultura Contemporânea, vol. 16, no. 43, p. 375-395, 2019. https://doi.org/10.5935/2238-1279.20190018.

ESTRELA, Maria Teresa. Questões de profissionalidade e profissionalismo docente. 2001. Ser Professor no Limiar do séc. XXI [...]. [S. l.]: ISET, 2001. p. 113-142.

FERREIRA, Liliana; BRAIDO, Luiza; MARASCHIN, Mariglei; TONI, Dulcineia. Estágio Supervisionado no Curso de Pedagogia: O que Dizem os Projetos Pedagógios e Quais Sentidos Produzidos por Egressos. Práxis Educacional, vol. 16, no. 43, p. 117-133, 2020. https://doi.org/https://doi.org/10.22481/rpe.v16i43.6774.

GALVÃO, Cecília; REIS, Pedro. O conhecimento profissional dos professores: O estágio de Sofia. Revista de Educação, vol. XI, no. 2, p. 165-178, 2002. Available at: http://hdl.handle.net/10451/4722.

GARMSTON, R; LIPTON, L; KAISER, K. A psicologia da supervisão. In: OLIVEIRAFORMOSINHO, Júlia (ed.). A supervisão na formação de professores II. Da organização à pessoa. [S. l.]: Porto Editora, 2002. p. $17-132$.

GATTI, Bernardete A.; NUNES, Marina Muniz Rossa (Orgs.). Formação de professores para o Ensino Fundamental: estudo de currículos das licenciaturas em Pedadogia, Língua Portuguesa, Matemática e Ciências Biológicas. [S. l.]: FCC-DPE (Coleção Textos FCC, vol. 29), 2009. Available at:

http://www.fcc.org.br/pesquisa/publicacoes/textos_fcc/arquivos/1463/arquivoAnexado.pdf. KOSTIAINEN, Emma; UKSKOSKI, Tuija; RUOHOTIE-LYHTY, Maria; KAUPPINEN, Merja; KAINULAINEN, Johanna; MÄKINEN, Tommi. Meaningful learning in teacher education. Teaching and Teacher Education, vol. 71, p. 66-77, 2018.

https://doi.org/10.1016/j.tate.2017.12.009.

KRUEGER, Richard A.; CASEY, Mary Anne. Focus groups: A practical guide for applied research. 5th ed. [S. l.]: Sage Publications, 2014.

KWIETNIEWSKI, Katelyn. Literature Review on Project-Based Learning. Career \& Technical Education Theses. 1, 2017. Available at:

http://digitalcommons.buffalostate.edu/careereducation_theses/1.

LASAUSKIENE, Jolanta; RAUDUVAITE, Asta. Project-Based Learning at University:

Teaching Experiences of Lecturers. Procedia - Social and Behavioral Sciences, vol. 197, p.

788-792, 2015. DOI 10.1016/j.sbspro.2015.07.182. Available at:

http://dx.doi.org/10.1016/j.sbspro.2015.07.182.

LEE, Jean S; BLACKWELL, Sue; DRAKE, Jennifer; MORAN, Kathryn A. Taking a Leap of Faith: Redefining Teaching and Learning in Higher Education Through Project-Based Learning. Interdisciplinary Journal of Problem-Based Learning, vol. 8, no. 2, p. 3-13, 2014. https://doi.org/10.7771/1541-5015.1426.

NICU, Adriana. Policy and Practice of Initial Teacher Training. Procedia - Social and Behavioral Sciences, vol. 180, p. 80-86, 2015. DOI 10.1016/j.sbspro.2015.02.089. Available at: http://dx.doi.org/10.1016/j.sbspro.2015.02.089.

NIEMI, Hannele. Active learning - A cultural change needed in teacher education and schools. Teaching and Teacher Education, vol. 18, no. 7, p. 763-780, 2002. https://doi.org/10.1016/S0742-051X(02)00042-2.

RANGEL, Manuel; GONÇALVES, Cláudia. A Metodologia de Trabalho de Projeto na nossa prática pedagógica. Da investigação às práticas, vol. I, no. 3, p. 21-43, 2011. .

SILVA, Maria. Projectos e Aprendizagens. 2005. Comunicação apresentada ao 2. ${ }^{\circ}$ Encontro de Educadores de Infância e Professores do $1^{\circ}$ Ciclo, Porto, 24-25 Fevereiro 2005 [...]. [S. l.]: Porto: Areal, 2005.

SMITH, Kari. Mentoring - a profession within a profession. In: TILLEMA, Harm; 
WESTHUIZEN, Gert van; SMITH, Kari (eds.). Mentoring for Learning - Climbing the mountain. [S. l.]: Sense publishers, 2015. p. 283-298.

SUTHERLAND, Louise; HOWARD, Sarah; MARKAUSKAITE, Lina. Professional identity creation: Examining the development of beginning preservice teachers' understanding of their work as teachers. Teaching and Teacher Education, vol. 26, no. 3, p. 455-465, 2010. DOI 10.1016/j.tate.2009.06.006. Available at: http://dx.doi.org/10.1016/j.tate.2009.06.006. TEMPERA, Tiago; TINOCA, Luís. Contributions of Project-Based Learning in Initial Teacher Education for Elementary School Teachers. 2020. Comunicação apresentada ao EDiTE Conference 2020 - International diversity in teacher and higher education research in the 21st century Conference [...]. [S. l.: s. n.], 2020. Available at: http://editeevents.elte.hu/.

VASCONCELOS, Teresa. Trabalho de Projeto como " Pedagogia de Fronteira ." Da investigação às práticas, vol. 1, no. 3, p. 8-20, 2011. .

VIRTUE, Emilie E.; HINNANT-CRAWFORD, Brandi N. "We're doing things that are meaningful": Student Perspectives of Project-based Learning Across the Disciplines. The Interdisciplinary Journal of Problem-based Learning, vol. 13, no. 2, 2019.

https://doi.org/https://doi.org/10.7771/1541-5015.1809.

VUJIČIĆ, L.; BONETA, Ž.; IVKOVIĆ, Ž. The (co-)construction of knowledge within initial teacher training: Experiences from Croatia. Center for Educational Policy Studies Journal, vol. 5, no. 2, p. 139-157, 2015. .

Referências legais

PORTUGAL. Decreto-Lei $n^{\circ}$ 43, de 22 de fevereiro de 2007. Define as condições necessárias à obtenção de habilitação profissional para a docência. Diário da República, 1 . $^{\mathrm{a}}$ série, n. $^{\circ} 38$.

Agradecimentos: Este trabalho foi financiado pela Fundação para a Ciência e a Tecnologia (FCT), em Portugal [bolsa número SFRH/BD/137693/2018].

\section{SOBRE OS AUTORES}

Tiago Bruno Correia Tempera. Doutorando em Educação. Professor Assistente de Pedagogia e Matemática na Escola Superior de Educação do Instituto Politécnico de Lisboa. Investigador do UIDEF - Unidade de Investigação e Desenvolvimento em Educação e Formação do Instituto de Educação da Universidade de Lisboa. Bolseiro da Fundação para a Ciência e a Tecnologia. Contribuição de autoria: Escrita - Primeira Redação.

Luís Alexandre da Fonseca Tinoca. Doutor em Educação. Professor Assistente no Instituto de Educação da Universidade de Lisboa. Investigador do UIDEF - Unidade de Investigação e Desenvolvimento em Educação e Formação do Instituto de Educação da Universidade de Lisboa. Contribuição de autoria: Escrita - Revisão e Edição.

\section{Como citar este artigo (ABNT):}

TEMPERA, Tiago Bruno Correia; TINOCA, Luís Alexandre da Fonseca. O trabalho de projeto na prática de ensino de futuros professores do ensino básico em Portugal . Revista Práxis Educacional, Vitória da Conquista, v. $18, \quad$ n. $49, \quad 2022$. https://doi.org/10.22481/praxisedu.v18i49.10072 